The new paradigm is fashioned around the use of models to interpret and exploit data and to develop products that encourage wide adoption and value-adding.

The degree of unanimity achieved by the Conference exceeded expectations, yet there is clearly much work remaining, both in terms of detail and in terms of enacting the recommendations. However the ocean community can look forward with some confidence to an era of great prospect and opportunity, and also one of enhanced responsibility. For oceanography and climate at least, the integrated global observing strategy is now being realized.

\section{Science Highlights from the Monsoon Sym- posium and CLIVAR Monsoon Panel Meeting}

\section{William K.-M. Lau}

Goddard Space Flight Center, NASA, Greenbelt, USA

lau@climate.gsfc.nasa.gov

The CLIVAR Asian-Australian (AA) Monsoon Panel held its second official meeting on December 8-10, 1999 at the EastWest Center, Honolulu, Hawaii. The panel meeting was preceded by a 2-day (Dec. 6-8) Monsoon Symposium to celebrate the careers of Profs. T. Murakami, and M. Yanai who are now both retired. The first day of the panel meeting was devoted to a Model Intercomparison Workshop, sponsored by the CLIVAR AA-Monsoon Panel in response to the CLIVAR SSG's call for focused efforts to improve our understanding of the causes and consequences of the massive ENSO disturbances of 1997-1998. Results were presented showing Atmospheric General Circulation Model (AGCM) performance in simulating monsoon circulation, for given Sea Surface Temperatures (SSTs). Further presentations examined the performance of Oceanic General Circulation Models (OGCMs) in simulating the observed SST anomalies (SSTAs), given observed or estimated surface fluxes. A summary of scientific highlights presented at the meetings are as follow:

- The monsoon is a coupled ocean-atmosphere-land phenomenon. Modelling and prediction of the monsoon and its variability requires the inclusion of all three components. In particular, the annual cycle of heat balance and oceanic transports in the Indian Ocean play a significant role in the annual cycle of the monsoon.

- Variability of the monsoon is influenced by, and probably influences, the ENSO phenomenon. However, the relationships are spasmodic and vary on interdecadal time scales.

- Intrinsic coupled monsoon rainfall-SST modes have been identified in the western Pacific and the Indian Ocean that contribute significantly to variability of monsoon intensity. Understanding of the physical make-up of these modes is crucial in unravelling fundamental mechanisms of monsoon-ENSO relationships.

- $\quad$ Regarding the existence of a strong biennial variability of the monsoon, a number of theories have been proposed invoking feedbacks between the land, ocean and atmosphere of the monsoon regime extending from the western Pacific Ocean, the Asian land mass and the Indian Ocean. However, like the ENSO-monsoon relationship, there appears to be interdecadal variability of the biennial signal.

- There are new findings suggesting that the Indian Ocean possesses coupled ocean-atmosphere modes that may be independent of ENSO. One of these modes occurs in the form of an oscillating east-west dipole in SST and precipitation. Whereas the relationship to monsoon variability is unclear, it is strongly correlated with the East African fall monsoon rains.

- New evidence suggests that regional components of the monsoon, i.e. the South Asian and the East Asian monsoons oscillate between active and break phases, which are related to intraseasonal oscillations on 40-60 day time scales. These fluctuations are associated with the "Madden-Julian oscillation" (MJO) but are modified by the strong north-south pressure gradient and basin-scale SST fluctuations that exist during the established monsoon. While the ISO may limit interannual monsoon predictability, it offers great promise for short-term ( weeks) monsoon forecasts.

- Interesting and significant results are coming out from recent field experiments e.g., SCSMEX, JASMINE and BOBMEX. For example, preliminary results from JASMINE indicates that the ocean-atmosphere heat flux during the established monsoon in the southern Bay of Bengal region is similar to the mean heat flux in the tropical Pacific warm pool. The variability of surface fluxes on intraseasonal time scales in the eastern Indian Ocean is very large, suggesting strong local air-sea interaction.

Deliberations at the Hawaii Panel Meeting provided a number of recommendations for action in the areas of modelling, process studies and long-term monitoring. These recommendations form the basis of a CLIVAR Monsoon Implementation Plan, which is being developed. For a preliminary draft of the Implementation Plan, please check the website http: / / climate.gsfc.nasa.gov/ kmkim/clivar /

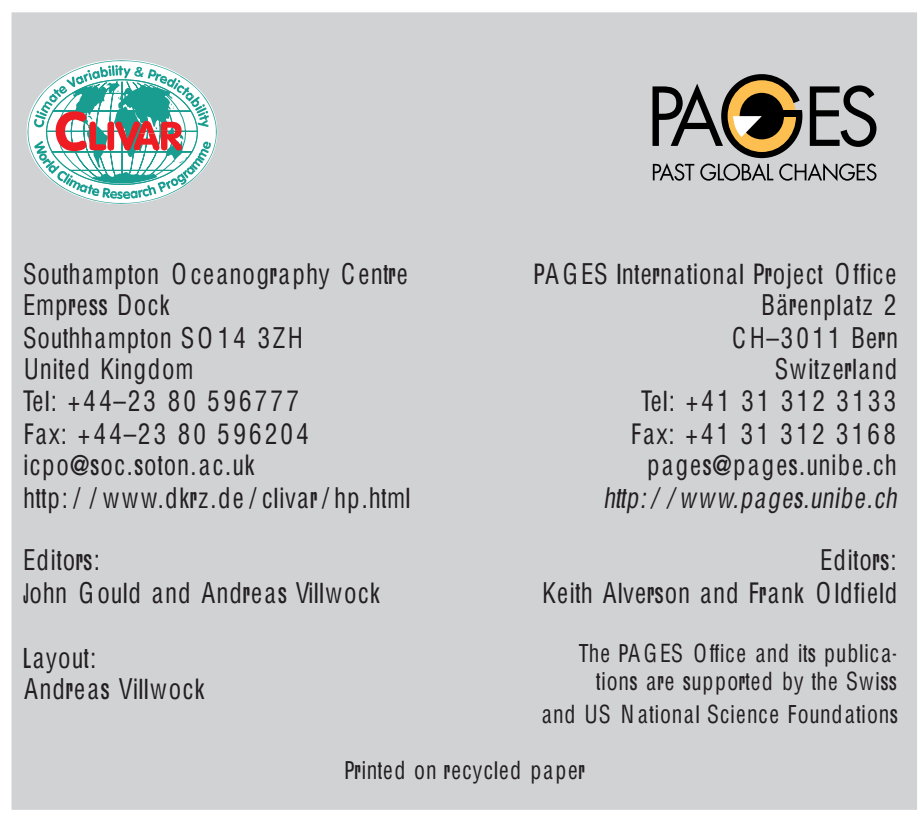

